DOI: https://doi.org/10.46630/bs.1.2019.01

UDK 316.334.2:316.32(497+4)

Иван Райчев ${ }^{1}$

ВТУ „Св. св. Кирил и Методий“

Философски факултет

Велико Търново

България

\title{
ИКОНОМИЧЕСКА И СОЦИАЛНА ТРАНСФОРМАЦИЯ В ЕВРОПА И НА БАЛКАНИТЕ ${ }^{2}$
}

\author{
Резюме
}

\begin{abstract}
Икономическата и социалната промяна днес преминава през процесите на глобализацията (глобалистиката). Кризисните явления в планетарен мащаб в икономиката и частност във финансовия сектор, е показателен, че т.нар. „реактивен модел“, предполагащ властническото поведение на олигарсите е достигнало апогея си, до критичната точка и е необходимо да се направи „ляв“ завой. Основният извод е „...че е необходима видимата ръка на държавата и междудържавните отношения, отколкото невидимата ръка на пазара“.
\end{abstract}

Ключови думи: икономическа и финансова политика, социална държава, солидарност, справедливост.

„Задачата на икономиката е“ - посочва Н. Агънски - „да открие и познае законите, които управляват и насочват икономическите явления и факти, а задачите на политиката са производни, вторични, т.е политиката е функция от икономиката, макар че политиката се стреми да регулира и координира икономическите отношения...“" И още: „В историческата действителност има само икономическа политика, а политическа икономия няма и не може да има“ (Агънски, 1948: 4). Акцентираме на това обстоятелство защото често пъти политиците игнорират този факт.

Наименованието „глобализъм“ и „глобализация“, са широко употребявани думи, които бързо се превърнаха в лозунг, в магическо заклинание за отключване вратите към всички настоящи и бъдещи мистерии. За едни това е задължение което трябва да правим, за други „глобализацията“ е причина за нашето нещастие. Безпорен е факта, че това е необратим процес. Това е видно и в ежедневието, в покупката на стоки произведени и доставени от различни краища на света. Всички те редовно да се транспортират по земното кълбо, като за координирането на милионите транзакции е необходим непрекъснат поток от информация.

Светът в редица отношения се е превърнал в единна социална система в резултат от нарастващите връзки на взаимозависимост, за-

1 ivan.r.raychev@gmail.com

2 Саопшење са научног скупа са међународним учешћем Традииија, модернизација $u$ идентитети Х: Биланс транзиције у Србији и на Балкану који је одржан на Филозофском факултету у Нишу 24. маја 2019. године. 
сягащи буквално всеки човек. Социалните, политическите и икономическите отношения, пресичащи границите на страните, в крайна сметка определят съдбата на тези, които живеят във всяка една от тях. Това предполага социологически анализ на глобалните процеси, като опазване на околната среда, предотвратяване на военни конфликти, икономически катаклизми.

Развитието на световните социални отношения включват и големи неравенства между индустриалните общества и обществата от Третия свят. Глобализацията засяга живота на хората във всички страни, богати и бедни, като променя не само глобалните системи, но и всекидневието на хората. Отговорност от всички и от всеки, това следва да е мотото към което трябва да се стремим.

Несъмнено човечеството е изправено пред редица проблеми в това число и пред предизвикателствата на икономическата криза, започнала като финансова криза /през 2008. год/, която обхвана всички страни и продължаваща до днес. Но още по-тревожно е, че се очаква по мнение на икономически експерти, нова по-голяма по мащабите си глабална икономическа криза, която ще се отрази на Балканските страни. На фона на кризисните явления съществува едно “уродливо" явление на неравенството във всичките му аспекти, разрива между демонстративно елитно потребление на малка част от човечеството и подтискащата бедност на голяма част от хората в планетарен мащаб. По данни на Европейската статистическа служба Евростат /20172018/, един процент от населението притежава приблизително 99,0\% от националните богатства в глобален мащаб. В регионален план, по данни на Евростат линията на бедността в България е 348 лв., а по стойност на Евростат 351 лв., т.е. 1,665,300 лица, или 23,4\% от населениета на страната са в границита на линията на бедността или лица в риск, 40\% жени и 37\% мъже. Всеки пети жител на Балканите живее в риск на бедност. В осем страни в ЕС /пак по данни на Евростат/ хората живеят в значителна по-висока степен на риск на бедност в т.ч. Република Сърбия - 25,4\%, Република Северна Македония $-21,5 \%$, Република България - 22\%, Румъния $-25,4 \%$. Що се касае за покупателна способност на хората живеещи в държавите в $\mathrm{EC}$, положението и трагичто. В Люксенберг жителите разполагат с 17,600 евро за закупуване на стоки и услуги, в България 3,800 евро, Сърбия 3,000 евро, Македония 2,700 евро. Това е в резултат на разликата в размера на БВП /Функция от икономичиския растеж/ на човек, а разликата между най-богатата и най- бедната страна в ЕС е 5,4 пъти. На 14 март 2019. година в България под патронажа на президенството се проведе крьгла маса на тема: „За конкурентността и просперираща българска политика“. Като обощение по тази част на изложението можем да посочим, че БВП на Румъния е $37 \%$ от стойността на всички балкански държави, България $12 \%$, Сърбия 8\%, а останалите $11 \%$ се поделят между Босна и Херциговина, Албания, Република Северна Македония, Косово и Черна гора. Няма да е пресилено ако посочим, че Алчността на банкерите и на богатите ще погуби света. И ето къде избива всичко това-глуха агресия без лидери и идеология. „Све- 
тът не може да продължава така. Една от причините за това са неимоверно нарастналите социални неравенства..." и по-нататък, от една страна, демокрацията е задала равни очаквания, от друга - не дава никакви знаци за това, че тези очаквания някой ден ще се осъществят. „Сгромолясва се модерния свят такъв, какъвто го познавахме досега“"? (Дичев, 2011). Идва ред на т. нар. “левый поворот”.

Кризисните явления в планетарен мащаб в икономиката и в частност във финансовия сектор, е показателен, че т.нар. "реактивен модел", предполагащ властническото поведение на олигарсите е достигнал апотея си, до критичната точка и е необходимо да се направи “ляв” завой. Така, че към настоящия момент на прага на левия завой се оказва целия свят. Къде се причините за глобалната криза, които ще се повторят.

Първо, отслабване и неефективност от държавното регулиране през последното десетилетие, “великия разрив” между глобалния характер на икономическите процеси в световен мащаб и локалния характер на регулативните системи.

Второ, съществуваща диспропорция между понятията "отговорност" и "право за вземане на решения" - Международният валутен фонд, Световната банка и националните правителства носят отговорностите.

Трето, съществуващ диктат на инвеститорите в глобалната икономическа система. Резултатът е, че зад “процъфтяващите” пазари се откроява пукнатина, която през 2008. година се “легитимира" чрез финансовата криза.

Четвърто, наличие на социална и национална безотговорност на “корпорацията на мениджърите”, моралната им ерозия, обособяването им в “каста", която не зависи от обществото, не се търси отговорност за управленческите им решения, личният им успех се определя от статуса им.

Пето, несъблюдаване на фундаментални закономерности на общественото развитие не само в икономическата област (например, цикличност в развитието), но и в диалектически план (спиралата на развитие). Старите парадигми трябва да се заменят с нови;

Шесто, неконтролеруемото използване на природните ресурси, скок на цените на енергоносителите, липса на иновации и зависимост на икономиката от външни фактори.

Днешният свят - глобалният, е по-различен от този на 20-те години на XX век и е зависим и „заложник на Уолт-стрийт“. И най-малките катаклизми и движения на американските пазари и действия на правителството са катализатор на негативни процеси. Това потвърждава тезата, че светьт е уязвим, той е монополярен и “американоцентричен”.

Отговор на глобалната криза неизбежно дава „глобалната перестройка“. Това понятие се появи преди повече от 25 години, чиято английска транскрипция “perestroika” се възприе най-безболезнено и в голяма степен се олицетворява с Михайл Горбачов. Не случайно финансовата криза, се изостри през септември 2009. година и бе сьпро- 
воден със скок на популярността на Барак Обама, като избирателите в

САЩ в голяма степен го олицетворяват с Михаил Горбачов през 90-те години на XX век.

Констатацията е, че 30-годишната доминация на чисто либералните идеи е приключила. Днес в света се наблюдава друга ситуация. Пребивавайки щастливо повече от четвърт век, рейгономиката в даден исторически момент се изчерпа. На прага “чука”, „неосоциализма“.

В близко бъдеще Кейнс ще бъде все повече необходим като идеология, освен Фридман и Хайек. Необходима е видимата ръка на държавата и междудържавните обединения, отколкото, невидимата ръка на пазара.

„Без олевяване няма да може“, посочва акад. Никола Попов и продължава: “Защото светът се променя. Олевяването означава повече самостоятелност и самотворчество. Това означава хората да чувстват потребността да работят за възхода на държавата, а не насилствено да им се налага от някого..." (Попов, 2012).

Необходим е ляв завой, но вече не тяснонационален и не регионален, а глобален, който да реши натрупаните проблеми през последните десетилетия. Възниква въпроса: „Отива ли си сощиалната държава"?

„Социалната държава е част от нашата тъкан, от нашия начин на живот, но има нужда от реформи. Това е ясно“, казва Емануил Мулен, икономически съветник на бившият френския призидент Никола Саркози.

До неотдавна в Европа държавните протекции и регулирания капитализъм създаваха усещането за стабилност и предвидимост от „от люлката до гроба“" на всеки жител в развитите страни. Фамилните субсидии подпомагат майките да гледат своите деца в къщи, лекарските прегледи са почти безплатни, образованието също. Пенсиите и обезщетенията при безработицата са щедри. Така, че едва ли някой си е представил живота без социалната държава. Тя бе създадена от благородни подбуди но идеализмът се сблъска със стената на финансовата реалност. Кои са предпоставките за това?

Едва ли само социалните разходи са причина за отслабената финансова позиция на запада, или има нещо друго? Струва ни се, както пише в-к „Таймс“, че „олялата се бюрокрация“ с неразумните данъчни политики, военни авантюри, банкови спасявания и неразумните кредите изиграха своята роля. Появи се понятието „Консуматорско общество“ характерно най-вече за богатите слоеве от населението. Това е страховита тенденция в глобален мащаб.

Социалните програми са част от икономиката, политиката и обществата на Запада, по тях хората планираха своите разходи, спестявания, образование, пенсиониране. „Свиването на социалната държава“ ще направи още по-трудно за Запада да избегне голямата рецесия и да намали безработицата.

Премахването на държавната подкрепа за средната класа и бедните ще засили неравенството в доходите и ще увеличи бедностma. 
Изминалите президенските избори в САЩ и Франция - раздират обществата, изправяйки богати срещу бедни, работници против мениджъри, държава срещу държава.

Изходът е, да се даде нов облик на икономиките и обществата на Запада в това число и на Балканите за десетилетия напред.

Основният проблем на социалната държава е да се намерят свежи пари. Никой обаче, не иска да изгуби привилегиите на социалната държава, но малцина биха искали да плащат за тях повече. Десетилетия напред САЩ и Европа заобикаляха това двуличие, злоупотребявайки с привилегированата си позиция в глобалната икономика. Те запушваха дупките в бюджета си, като издаваха облигации на международния капиталов пазар на минимални цени.

Трупайки планини от дългови, западните демокрации разклатиха силно доверието на инвеститорите в дългосрочната финансова стабилност и резултатьт е „кризата в еврозоната“.

Натискът на финансовите обстоятелства „натиснаха“ Запада и САЩ към безпрецидентни ограничения. Последствията вероятно ще са непредвидими, защото средния американец и европеец станаха по-зависими от социалните политики. Милиони държавни служители в цяла Европа протестираха. Недоволните окупираха мадритските площади, демонстрациите станаха ежедневие в Атина и Рим. В САЩ Движението „Окупирай Уолстрийт“ се превърнаха в национален протест срещу спада на жизнения стандарт на работническата класа, а според неофициални данни богатите са се увеличили приблизително със 16 на сто в световен мащаб. Анализаторите се питат: „Къде e социалната справедливост, съществува ли такава в съвременните обиества" ?

Жан Пол Фитуси, директор на института за икономическа конюктура, предупреждава, че драстичната реформа на социалната държава може да подкопае социалната стабилност на Европа, което е предпоставка за възникването на голям политически проблем.

Баталията около социалната държава задълбочава разделението на обществото, вече възпалено от отварящата се ножица в доходите и глобализацията. Поддръжниците на социалната държава виждат в свиването и нова форма на класова война, в която богатите манипулирайки политическата система, прехвърлят бремето, фискалните реформи на хората, който най-малко могат да си го позволят. На Генералната конференция на труда в Париж администраторьт Мишел Донед изтъква, че социалната държава няма вина за френските икономически беди. Истинският виновник според него е икономическият либерализъм.

Изходът не е в орязването на бюджетите, а да се намери свеж финансов ресурс. Това означава да се „изцедят“ големите компании и богатите капиталисти с яки данъци. Предизвикателството към политиците е огромно.

Рецептата от която се нуждае Западът, е завръщането към духа на социалната държава, към онова, което наричахме свобода, солидарност и справедливост - взаимни саможертви в името на обществе- 
ното благо. Но докато консерватори и либерали, бедни и богати, синдикалисти и мениджъри се надпреварват в безплоден опит да запазят привилегии или да търсят политически девиденти, солидарността се губи като идея и въжделение за милиони хора.

Какво следва по-нататьк, какво трябва да се направи?

Първо, засилване ролята на държавата като регулатор на икономическите процеси, но не като субект и не в качеството си на инструмент на преразпределение на собствеността и финансовите потоци в полза на едни или други корпоративни и частни интереси.

Второ, привеждане на регулативната система в съответствие с изискванията на глобалната икономика и равновесие на ключовите субекти в нея-формиране на „световно икономическо правителство“.

Трето, утвърждаване солидарността като ценност и алтернатива на икономическия егоизъм и неуправляемата конкуренция. Това засяга не само пазарните субекти, но и цели страни и региони.

Четвърто, въвеждане на по-строги изисквания към собствениците и мениджърите от страна на държавата и обществото. Необходимо е в мениджмънта да се утвърдят т.нар. „неопатриархални ценности“: морал; лична отговорност ; семейна приемственост; дългосрочно планиране.

Пето, нова система на управление на финансовите пазари и тяхното регулиране, което предполага баланс на тяхната дейност от гледна точка на обществените цели, поддържащи реално развитие на икономиката. Финансовата криза е криза на финансовия елит.

Шесто, ограничаване на безпределното забогатяване на т.нар. “златни милионери” и въвеждането на ценностни самоограничения, което да се превърне във философия на мениджмънта.

Седмо, ускорена разработка и въвеждане на конкретни технологични процеси, съкращаващи използването на невъзобновяеми природни ресурси-алтернативна енергетика - нефт, газ.

Осмо, частично възобновяване ценностите и стандартите на индустриалната епоха в противовес на придобитите чрез гротеска разрастването на виртуалния сектор. Предпоставки за създаване на нови възможности за малкия и средния бизнес, а същевременно и база за бъдещ “десен” завой.

Девето, установяване на порядък в движението на капиталите, стоките и работната сила което рефлектира върху пазара на труда.

Десето, вниманието на националните правителства и международните корпорации трябва да бъде насочено към създаването на т. нар. „мека безопасност“, т.е. създаването на ефективна социална защита (,безопасна възглавница“).

Единадесето, особено внимание следва да се отдели на човешкия фактор и интелект както в икономическа област, така и в другите такива, чрез творчески и критически подход към него, позволяващи реализирането на творческите способности.

Дванадесето, на заден план следва да се постави търговската печалба и прословутия икономически егоизъм. Следва да се разработват и финансират стратегически проекти (здравеопазване, образование, 
околна среда), които не са печеливши в средносрочна перспектива, но са дългосрочно целесъобразни. Здрава и образована нация, това е еталона на проспериращата нащия.

Основателно се задава въпросът: „Световната криза ще доведе ли до крах либерализма в световен мащаб?“. Безусловно не.

В началото на 80 те годинина XX век неолиберализмът се оказа ефективен като комплекс от социалистически идеи и практики. Тържеството на либерализма доведе след себе си становища и мнения, като пример Френсис Фукояма, чийто пророчество за либерализма е „края на историята“" и „последици за глобалния човек“.

Днес в началото 21 век като че ли "победителят" е неосоииализмът. Това не трябва да се разбира като тоталитарен социализъм от Ялтенски тип, който бе предпоставка за неолиберализма на Роналд Рейгън и Маргрет Тачър. По-нататъшната глобализация ще бъде отчасти забавена, но не и спряна. “Златните милионери” следва да се откажат за още по-голямо увеличение на своя потребителски статус, но високият им стандарт на потребление, установил се в края на 20 век, ще остане непроменен. Силата към политическата свобода и откритата конкуренция на идеи не ще изчезне. Прогнозата на Фукояма формално не е оправдана, но много негови оценки са верни що се отнася до световния “ляв" завой. През следващите 15-20 години, така както неосоциализмът разчиства натрупаното от глобалната криза и хармонизирането на световната икономика ще започне нов етап на настъпление на либерализма. Отвъд “левия” завой отново ще настьпи “десен”. Това е "поканата" на утрешния ден.

Цикличността ще се повтаря пред определен период от време (социален и икономически детерминизъм).

Глобализацията изменя същността на основните процеси в съвременния свят, и изисква нови подходи към предизвикателствата на обкръжаващата среда. Основна грижа на всяка държава в съвременното глобализиращо общество е да изпраща в световното публично пространство послания, които да изграждат максимално доверие към нея, да постигнат ефективна диалогичност и да формират нейния благоприятен имидж.

Отпечатъкът на глобализацията върху демократичните процеси предполага анализ на концепциите за хуманизиране на глобализащията, „за справедлива“ и равноправна глобализачия, която да носи положителни резултати за всички, за обвързването на икономическите промени със социалната сигурност на човека. Докладите и световните конференции на организации в системата на ООН по проблемите на глобализацията могат и трябва да се разглеждат като инструменти на публичната комуникация за постигане на глобализация с човешко лице

Следва да се отдели подобаващо внимание и на разнообразието от PR стратегиите в сложната връзка между глобализацията и демокрацията. Въздействието на PR стратегиите следва да се разглежда като рожба на светлата част на глобализацията, като инструмент за нейното хуманизиране. 
Внимание заслужава глобалното като стратегия и локалното/ за Балканските страни/като практика в различни сфери - икономическа, политическа, културна. Да се вникне в това, какво се “крие” зад понятието “глокализация", формирано от глобалното и локалното, които влизат едно в друго и се смесват, през призмата на глобалните и регионалните зависимости.

\section{БИБЛИОГРАФИЯ}

Агънски, Н. Социология - част 1. София, 1948.

Бауман, З. Глобализацията. Последищите за човека. София, 1999.

Бек, Улрих. Световното рисково общество. София, 2001.

Гълбрайт, Джон. Анатомия на властта. София, 1993.

Близнаков, П. Популярна соииология. Варна, 2006.

Драганов, Д. „Какво раждат младежките бунтове“. 24 часа 224 (2011).

Дичев, Ив. „Сгромолясва ли се модерния свят, какъвто го познаваме“. 24 часа 219 (2011).

Иванова, А. Какъв труд е нужен на човека. София, 2000.

Икономика и сочиология (Антология). София: „Лик“, 1999.

Кацарски, Ив. „Икономикс и икономическа социология - спор на дисциплините“. Икономически перспективи 5 (2011).

Кенън, П. Залезът на демокрацията. София,1995.

Марковић, Д. Глобалистика и криза глобалне економије. Београд, 2010.

Митрович, Л. Преходът към периферен капитализъм. София, 2010.

Райчев, И. Социология на глобализаџията. Велико Търново: „Фабер“, 2010.

Ростоу, У. Стадии на икономическия растеж. София, 1995.

„Социалната държава, каквато я знаем, си отива“. 24 часа 322 (2011).

Стоянов, Хр. Хуманизация на труда. София, 1985.

Тофльр, Ал. Третата вълна. София: „Пейо Яворов“, 1991.

Фукуяма, Ф. Доверие. София, 1999.

Coper, P. Sociology - An Introduction course. L, 1998.

Giacobbi, M., J.P.-Roux. Initiation a la sociologie. Paris, 1990.

Smelser, Joseph. History of economic analysis. London, Georg Allen \& Unwin, 1954.

Wiswede, G. Soziologie, Landsberg, 1991. 


\section{ECONOMIC AND SOCIAL TRANSFORMATION PROCESSES IN EUROPE AS A WHOLE AND THE BALKANS IN PARTICULAR}

\section{Summary}

Nowadays any economic and social changes are directly linked to the process of globalization. Economic crises on a global scale, particularly within the financial sector, are indicative of the so-called "reactive model" of economic development, which in itself would indicate that the political dominance of oligarchs has reached a critical level and a metaphorical "left turn" is needed. Our main conclusion would be that "... what is required is the perceivable hand of the administration and international relations, rather than the invisible hand of the market".

Key words: economic and financial policy, welfare state, solidarity, social justice. 